\title{
A Putative Mechanism for Bog Patterning
}

\author{
M. Rietkerk, ${ }^{1, *}$ S. C. Dekker, ${ }^{1, \dagger}$ M. J. Wassen, ${ }^{1, \ddagger}$ A. W. M. Verkroost, ${ }^{1, \S}$ and M. F. P. Bierkens ${ }^{2, \|}$
}

1. Department of Environmental Sciences, Utrecht University, Heidelberglaan 2, 3584 CS Utrecht, The Netherlands; 2. Department of Physical Geography, Utrecht University, Heidelberglaan 2, 3584 CS Utrecht, The Netherlands

Submitted August 7, 2003; Accepted December 3, 2003; Electronically published May 4, 2004

ABSTRACT: The surface of bogs commonly shows various spatial vegetation patterning. Typical are "string patterns" consisting of regular densely vegetated bands oriented perpendicular to the slope. Here, we report on regular "maze patterns" on flat ground, consisting of bands densely vegetated by vascular plants in a more sparsely vegetated matrix of nonvascular plant communities. We present a model reproducing these maze and string patterns, describing how nutrient-limited vascular plants are controlled by, and in turn control, both hydrology and solute transport. We propose that the patterns are self-organized and originate from a nutrient accumulation mechanism. In the model, this is caused by the convective transport of nutrients in the groundwater toward areas with higher vascular plant biomass, driven by differences in transpiration rate. In a numerical bifurcation analysis we show how the maze patterns originate from the spatially homogeneous equilibrium and how this is affected by changes in rainfall, nutrient input, and plant properties. Our results confirm earlier model results, showing that redistribution of a limiting resource may lead to fine-scale facilitative and coarse-scale competitive plant interactions in different ecosystems. Self-organization in ecosystems may be a more general phenomenon than previously thought, which can be mechanistically linked to scale-dependent facilitation and competition.

Keywords: hydrology, nutrient limitation, ombrotrophic, selforganization, solute transport, spatial patterns, vegetation patterns.

The surface of bogs in North America and Eurasia commonly shows various spatial patterning of hummocks and

\footnotetext{
* E-mail: m.rietkerk@geog.uu.nl.

† E-mail: s.dekker@geog.uu.nl.

‡ E-mail: m.wassen@geog.uu.nl.

` E-mail: a.verkroost@geog.uu.nl.

" E-mail: m.bierkens@geog.uu.nl.
}

Am. Nat. 2004. Vol. 163, pp. 699-708. (c) 2004 by The University of Chicago. 0003-0147/2004/16305-40052\$15.00. All rights reserved. hollows (Sakaguchi 1980; Lindsay et al. 1985; Belyea and Lancaster 2002). Characteristic are the "string patterns" (Sakaguchi 1980; Foster et al. 1983) consisting of regular densely vegetated bands (hummocks forming ridges) oriented perpendicular to the slope, alternating with wetter zones that are more sparsely vegetated (hollows forming pools). Current theoretical and empirical investigations show that spatial patterning in itself could be explained by a positive feedback between total plant productivity and thickness of the acrotelm (upper layer of peat) on slightly elevated, dryer sites, mainly because of increased production of vascular plants (Alexandrov 1988; Swanson and Grigal 1988; Belyea and Clymo 2001). Thus, a bog surface with slight initial differences between more densely vegetated, dryer sites and wetter sites that are more sparsely vegetated may further differentiate and exhibit spatial patterning. We call this the "positive feedback" mechanism.

The positive feedback mechanism alone cannot account for any regularity in spatial patterns, such as the observed string patterns. Swanson and Grigal (1988) propose a stochastic, nonmechanistic model of bog patterning, and they mimic the positive feedback mechanism by simply assuming that as the water table is lowered the probability of hummock formation increases. This model suggests that regular string patterns develop only if the slope of a bog surface is steep enough that ponding of surface water upstream from hummocks affect the distribution of future hummocks. We call this the "water ponding" mechanism.

We agree with the assertion of Swanson and Grigal (1988), and we acknowledge that the mechanism they propose may indeed operate. However, as we will argue, the distribution of regular string patterns is not necessarily restricted to the specific conditions suggested by their model. Moreover, we report on regular spatial vegetation patterns on flat ground, consisting of spatially extensive "maze patterns"-bands densely vegetated by mainly vascular plants in a more sparsely vegetated matrix of predominantly nonvascular plant communities (fig. 1). These patterns have been observed in the great Vasyugan bog complex in western Siberia $\left(57^{\circ}-59^{\circ} \mathrm{N}, 76^{\circ}-83^{\circ} \mathrm{E}\right)$, where peat accumulation started around 10,500 years BP and permafrost conditions came to an end around 11,000 years BP (Lapshina et al. 2001). Because of their form and reg- 
ularity, and due to the lack of slope, these maze patterns cannot be explained either by the positive feedback mechanism alone or by the water ponding mechanism.

Here, we show by means of a deterministic, mechanistic
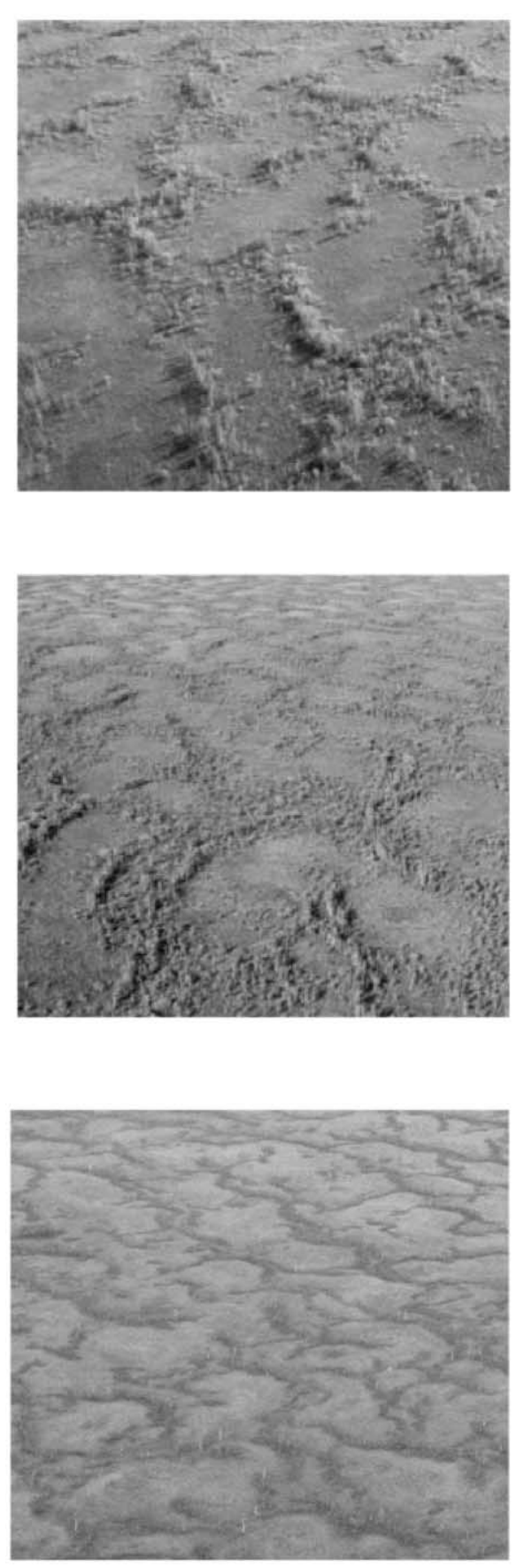

Figure 1: Oblique aerial photographs from maze patterns in the great Vasyugan bog complex (western Siberia). Photos taken by W. Bleuten, E. Lapshina, and M. J. Wassen. model that both maze and string patterns may be the result of spatial self-organization caused by a different mechanism, contesting the restricted conditions that must be met according to Swanson and Grigal (1988). The mechanism we propose is the convective transport of nutrients in the groundwater toward areas with higher vascular plant biomass driven by differences in transpiration rate (Fitter and Hay 1983; Marschner 1995). We call this the "nutrient accumulation" mechanism. So, if water flow is one directional, and plant productivity is mainly limited by nutrient flows, this mechanism may lead to the observed string patterns on slopes, while on flat ground maze patterns may develop. Further, in a numerical bifurcation analysis of the model we show how maze patterns originate from the spatially homogeneous equilibrium and how this is affected by changes in some relevant abiotic and plant properties. Finally, we will discuss the main model results and reveal a common principle explaining vegetation patterning in different ecosystems.

\section{The Model}

The model is a set of three partial differential equations describing the dynamics of three state variables in horizontal $x$ and $y$ direction: vascular plant biomass ( $B$; grams biomass $\left.\left[\mathrm{g}_{\mathrm{B}}\right] \mathrm{m}^{-2}\right)$, hydraulic head $(H ; \mathrm{m})$, and nutrient concentration in the groundwater $([N]$; grams nutrient $\left.\left[\mathrm{g}_{\mathrm{N}}\right] \mathrm{m}^{-3}\right)$. The dynamics of each state variable is described by a reaction term and a convection and/or a diffusion term. We opted to keep the number of state variables and parameters to a minimum. In this way, we reduce complexity while increasing generality. Furthermore, the effects of the nutrient accumulation mechanism can be studied in isolation.

\section{Plant Biomass}

We assume that vascular plant biomass reaction is determined by plant growth, plant loss to the nutrient compartment, and other plant losses. Plant growth is nutrient limited (Wassen et al. 1995), and specific plant growth increases linearly with increasing plant-specific nutrient uptake (De Angelis 1992; Rietkerk and van de Koppel 1997). Furthermore, water stress may occur when pressure head is reduced, leading to a decrease of plant growth. These assumptions lead to the following differential equation:

$$
\frac{d B}{d t}=g[N] B f(h(H))-d B-b B
$$

where $t$ is time $(\mathrm{yr}), \mathrm{g}$ is a plant growth parameter $\left(\mathrm{m}^{3}\right.$ $\left.\mathrm{g}_{\mathrm{N}}^{-1} \mathrm{yr}^{-1}\right), h$ is pressure head $(\mathrm{m}), f(h(H))$ is a soil water 
stress function (dimensionless; explained in "Hydraulic Head"), $d$ is the fractional return in litter $\left(\mathrm{yr}^{-1}\right)$, and $b$ is the fractional export or loss from the landscape $\left(\mathrm{yr}^{-1}\right)$. Plant seed dispersal, or lateral growth, is approximated by a diffusion term (Okubo 1989; cf. Rietkerk et al. 2002). So the full equation describing the rate of change of plant biomass is given by

$$
\frac{\partial B}{\partial t}=g[N] B f(h(H))-d B-b B+D_{\mathrm{B}}\left(\frac{\partial^{2} B}{\partial x^{2}}+\frac{\partial^{2} B}{\partial y^{2}}\right),
$$

where $D_{\mathrm{B}}$ is a diffusion coefficient for biomass $\left(\mathrm{m}^{-2} \mathrm{yr}^{-1}\right)$.

\section{Hydraulic Head}

The rate of change of hydraulic head is related to precipitation, transpiration of vascular plants, and soil evaporation. Transpiration is assumed to increase linearly with plant biomass but will decrease with increasing water stress (Feddes et al. 1978). Thus, the reaction of hydraulic head can be described by

$$
\frac{d H}{d t}=\frac{p}{\Theta}-\frac{t_{\mathrm{v}} B f(h(H))}{\Theta}-\frac{e f(h(H))}{\Theta},
$$

in which $p$ is precipitation $\left(\mathrm{m} \mathrm{yr}^{-1}\right), t_{\mathrm{v}}$ is a vascular plant transpiration parameter $\left(\mathrm{m}^{3} \mathrm{~g}_{\mathrm{B}}^{-1} \mathrm{yr}^{-1}\right), e$ is an evaporation parameter $\left(\mathrm{m} \mathrm{yr}^{-1}\right)$, and $\Theta$ is soil porosity (dimensionless). Note that all water amounts contribute to water column height, and dividing by porosity gives hydraulic head. The soil water stress function $f(h(H))$ is related to hydraulic head $H$ as follows. Pressure head $h(\mathrm{~m})$ is the difference between hydraulic head $H(\mathrm{~m})$ and elevation head $z(\mathrm{~m})$ : $h(H)=H-z$. We assume that there is no water stress; hence $f(h(H))=1$ if pressure head $h \geq h_{1}$, so $h_{1}(\mathrm{~m})$ is the pressure head below which soil water stress occurs. Soil water stress increases linearly with decreasing pressure head and arrives at its maximum; hence $f(h(H))=0$ if pressure head $h \leq h_{2}$, so $h_{2}(\mathrm{~m})$ is the pressure head below which no transpiration, evaporation, or plant growth occurs. Note that $h_{2}$ mimics rooting depth. For $h_{1} \geq h \geq$ $h_{2}$, the soil water stress function is described with the equation $f(h(H))=\left(h-h_{2}\right) /\left(h_{1}-h_{2}\right)$ (Feddes et al. 1978).

Volume flux of water in $x$ direction is based on Darcy's law:

$$
Q=-k A \frac{\partial H}{\partial x}
$$

where $Q$ is volume flux $\left(\mathrm{m}^{3} \mathrm{yr}^{-1}\right), k$ is hydraulic conductivity $\left(\mathrm{m} \mathrm{yr}^{-1}\right)$, and $A$ is the wetted area $\left(\mathrm{m}^{2}\right)$. Dividing both sides of the equation by $A \Theta$ gives the average pore water velocity:

$$
v=\frac{Q}{A \Theta}=\frac{-k(\partial H / \partial x)}{\Theta},
$$

where $v$ is the average pore water velocity $\left(\mathrm{m} \mathrm{yr}^{-1}\right)$. Water convection in $x$ direction is given by

$$
J_{\Theta H}=v H \Theta
$$

where $J_{\ominus H}$ is water convection $\left(\mathrm{m}^{2} \mathrm{yr}^{-1}\right)$. Substituting this term in the continuity equation (in $\mathrm{m} \mathrm{yr}^{-1}$ ) gives

$$
\Theta \frac{\partial H}{\partial t}=-\frac{\partial J_{\Theta H}}{\partial x}=-\frac{\partial(v H \Theta)}{\partial x} .
$$

Note that we can now substitute $v$ in this equation:

$$
\Theta \frac{\partial H}{\partial t}=-\frac{\partial\left\{H \Theta \frac{[-k(\partial H / \partial x)]}{\Theta}\right\}}{\partial x} .
$$

Assuming both $\Theta$ and $k$ to be constant, dividing by porosity $\Theta$ and rearranging gives

$$
\frac{\partial H}{\partial t}=\frac{k}{\Theta} \frac{\partial}{\partial x}\left(H \frac{\partial H}{\partial x}\right)
$$

The same counts for the water convection in $y$ direction; thus, the hydraulic head convection term becomes

$$
\frac{\partial H}{\partial t}=\frac{k}{\Theta}\left[\frac{\partial}{\partial x}\left(H \frac{\partial H}{\partial x}\right)+\frac{\partial}{\partial y}\left(H \frac{\partial H}{\partial y}\right)\right] .
$$

So the full equation describing the rate of change of hydraulic head is given by

$$
\begin{aligned}
\frac{\partial H}{\partial t}= & \frac{p}{\Theta}-\frac{t_{\mathrm{v}} B f(h(H))}{\Theta}-\frac{e f(h(H))}{\Theta} \\
& +\frac{k}{\Theta}\left[\frac{\partial}{\partial x}\left(H \frac{\partial H}{\partial x}\right)+\frac{\partial}{\partial y}\left(H \frac{\partial H}{\partial y}\right)\right] .
\end{aligned}
$$

\section{Nutrient Availability}

The rate of change of nutrient availability is related to nutrient input (e.g., atmospheric nutrient deposition), uptake by plants, recycling of dead plant material, and nutrient losses (De Angelis 1992). Nutrient input and specific nutrient losses are kept constant, whereas plant-specific 
Table 1: Overview of symbols used, their interpretation, units, and assigned values

\begin{tabular}{|c|c|c|c|}
\hline Symbol & Interpretation & Unit & Assigned value \\
\hline$B$ & Plant biomass & $\mathrm{g}_{\mathrm{B}} \mathrm{m}^{-2}$ & $\ldots$ \\
\hline$H$ & Hydraulic head & $\mathrm{m}$ & $\ldots$ \\
\hline$N$ & Nutrient availability & $\mathrm{g}_{\mathrm{N}} \mathrm{m}^{-2}$ & $\ldots$ \\
\hline$[N]$ & Nutrient concentration & $\mathrm{g}_{\mathrm{N}} \mathrm{m}^{-3}$ & $\ldots$ \\
\hline$g$ & Plant growth parameter & $\mathrm{m}^{3} \mathrm{~g}_{\mathrm{N}}^{-1} \mathrm{yr}^{-1}$ & Between .1 and .2 \\
\hline$d$ & Recycling parameter & $\mathrm{yr}^{-1}$ & .1 \\
\hline$b$ & Plant loss parameter & $\mathrm{yr}^{-1}$ & .2 \\
\hline$D_{\mathrm{B}}$ & Diffusion coefficient for biomass & $\mathrm{m}^{2} \mathrm{yr}^{-1}$ & 2 \\
\hline$p$ & Precipitation & $\mathrm{m} \mathrm{yr}^{-1}$ & Between .25 and .75 \\
\hline$t_{\mathrm{v}}$ & Plant transpiration parameter & $\mathrm{m}^{3} \mathrm{~g}_{\mathrm{B}}^{-1} \mathrm{yr}^{-1}$ & .005 \\
\hline$h$ & Pressure head & $\mathrm{m}$ & $\ldots$ \\
\hline$h_{1}$ & Pressure head below which soil water stress occurs & $\mathrm{m}$ & 0 \\
\hline$h_{2}$ & Root depth & $\mathrm{m}$ & Between -.9 and -.5 \\
\hline$e$ & Evaporation parameter & $\mathrm{m} \mathrm{yr}^{-1}$ & .3 \\
\hline$k$ & Hydraulic conductivity & 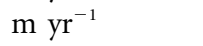 & 500 \\
\hline$\theta$ & Soil porosity & Dimensionless & .7 \\
\hline$N_{\text {in }}$ & Nutrient input & $\mathrm{g}_{\mathrm{N}} \mathrm{m}^{-2} \mathrm{yr}^{-1}$ & Between 0 and 5 \\
\hline$u$ & Plant uptake parameter & $\mathrm{m}^{3} \mathrm{~g}_{\mathrm{B}}^{-1} \mathrm{yr}^{-1}$ & .002 \\
\hline$r$ & Nutrient loss parameter & $\mathrm{yr}^{-1}$ & .1 \\
\hline$D_{\mathrm{N}}$ & Diffusion coefficient for nutrients & $\mathrm{m}^{2} \mathrm{yr}^{-1}$ & 10 \\
\hline
\end{tabular}

nutrient uptake increases linearly with nutrient concentration (Marschner 1995).

So the reaction of nutrient availability is governed by

$$
\frac{d N}{d t}=N_{\text {in }}-u[N] B f(h(H))+d \frac{u}{g} B-r N
$$

where $N$ is nutrient availability (in $\mathrm{g}_{\mathrm{N}} \mathrm{m}^{-2}$ ), $N_{\text {in }}$ is nutrient input $\left(\mathrm{g}_{\mathrm{N}} \mathrm{m}^{-2} \mathrm{yr}^{-1}\right), u$ is a plant uptake parameter $\left(\mathrm{m}^{3}\right.$ $\left.\mathrm{g}_{\mathrm{B}}^{-1} \mathrm{yr}^{-1}\right)$, and $r$ is a nutrient loss parameter $\left(\mathrm{yr}^{-1}\right)$. Note that the term $d u / g$ is the nutrient release as a consequence of plant mortality $d$, whereby $g / u$ is the carbon/nutrient ratio of the plant material $\left(\mathrm{g}_{\mathrm{B}} / \mathrm{g}_{\mathrm{N}}\right)$.

Because lateral nutrient flows depend on nutrient concentrations in the groundwater, we first rewrite equation (12) for nutrient concentrations (in $\mathrm{g}_{\mathrm{N}} \mathrm{m}^{-3}$ ). We can write

$$
\frac{d N}{d t}=\frac{d([N] H \Theta)}{d t}=H \Theta \frac{d[N]}{d t}+[N] \Theta \frac{d H}{d t} .
$$

Rearranging yields the following equation:

$$
\frac{d[N]}{d t}=\frac{(d N / d t)-[N] \Theta(d H / d t)}{H \Theta}
$$

Note that the term $d H / d t$ is described by equation (11) and that nutrient concentration in the groundwater depends on changes in hydraulic head because of diluting and condensing. Substituting equation (12) in equation (14) results in

$$
\begin{gathered}
\frac{d[N]}{d t}= \\
\frac{N_{\text {in }}-u[N] B f(h(H))+d(u / g) B-r N-[N] \Theta(d H / d t)}{H \Theta} .
\end{gathered}
$$

Lateral nutrient flow is related to two processes that operate simultaneously: nutrient convection, where dissolved nutrients adopt the velocity of groundwater flow according to the law of Darcy, and nutrient diffusion, approximated by the law of Fick. Nutrient convection in the $x$ direction can be described by

$$
J_{\mathrm{Ncon}}=v[N] \text {, }
$$

where $J_{\mathrm{Ncon}}$ is the nutrient convection $\left(\mathrm{g}_{\mathrm{N}} \mathrm{m}^{-2} \mathrm{yr}^{-1}\right)$ and $v$ is the average pore water velocity $\left(\mathrm{m} \mathrm{yr}^{-1}\right)$, assuming that dissolved nutrients move with the same velocity as soil water. Substituting this term in the continuity equation (in $\mathrm{g}_{\mathrm{N}} \mathrm{m}^{-3} \mathrm{yr}^{-1}$ ) gives

$$
\frac{\partial[N]}{\partial t}=-\frac{\partial J_{N c o n}}{\partial x}=-\frac{\partial(v[N])}{\partial x} .
$$

By substituting $v$, this becomes

$$
\frac{\partial[N]}{\partial t}=-\frac{\partial\left\{[N] \frac{[-k(\partial H / \partial x)]}{\theta}\right\}}{\partial x} .
$$


We can now write

$$
\frac{\partial[N]}{\partial t}=\frac{k}{\Theta} \frac{\partial}{\partial x}\left([N] \frac{\partial H}{\partial x}\right)
$$

The same counts for nutrient convection in $y$ direction; thus, the nutrient convection term becomes

$$
\frac{\partial[N]}{\partial t}=\frac{k}{\Theta}\left\{\frac{\partial}{\partial x}\left([N] \frac{\partial H}{\partial x}\right)+\frac{\partial}{\partial y}\left([N] \frac{\partial H}{\partial y}\right)\right\}
$$

Furthermore, nutrients also diffuse in $x$ direction, and this nutrient flux follows the law of Fick:

$$
J_{\mathrm{Ndif}}=-D_{\mathrm{N}} \frac{\partial[N]}{\partial x}
$$

where $J_{\text {Ndif }}$ is the nutrient flux $\left(\mathrm{g}_{\mathrm{N}} \mathrm{m}^{-2} \mathrm{yr}^{-1}\right)$ and $D_{\mathrm{N}}$ is a diffusion coefficient for nutrients $\left(\mathrm{m}^{2} \mathrm{yr}^{-1}\right)$. Substituting this in the continuity equation (in $\mathrm{g}_{\mathrm{N}} \mathrm{m}^{-3} \mathrm{yr}^{-1}$ ) gives

$$
\frac{\partial[N]}{\partial t}=-\frac{\partial J_{\mathrm{Ndif}}}{\partial x}=D_{\mathrm{N}} \frac{\partial^{2}[N]}{\partial x^{2}} .
$$

The same counts for the nutrient flux in $y$ direction; thus, the nutrient diffusion term becomes

$$
\frac{\partial[N]}{\partial t}=D_{\mathrm{N}}\left(\frac{\partial^{2}[N]}{\partial x^{2}}+\frac{\partial^{2}[N]}{\partial y^{2}}\right)
$$

So the full equation describing the rate of change of nutrient availability is given by

$$
\begin{gathered}
\frac{\partial[N]}{\partial t}= \\
\frac{N_{\text {in }}-u[N] B f(h(H))+d(u / g) B-r N-[N] \Theta(\partial H / \partial t)}{H \Theta} \\
+D_{\mathrm{N}}\left(\frac{\partial^{2}[N]}{\partial x^{2}}+\frac{\partial^{2}[N]}{\partial y^{2}}\right)+\frac{k}{\Theta}\left\{\frac{\partial}{\partial x}\left([N] \frac{\partial H}{\partial x}\right)+\frac{\partial}{\partial y}\left([N] \frac{\partial H}{\partial y}\right)\right\}
\end{gathered}
$$

Thus, the full model is given by equations (2), (11), and (24). Table 1 provides an overview of symbols used, their interpretation, units, and assigned values.

\section{Parameterization and Analysis}

Realistic ranges for the parameter combination $g / u$, reflecting the carbon/nutrient ratio of the plant material, were checked against measured values in west Siberian ombrotrophic bogs (Yefremov and Yefremova 2001), and

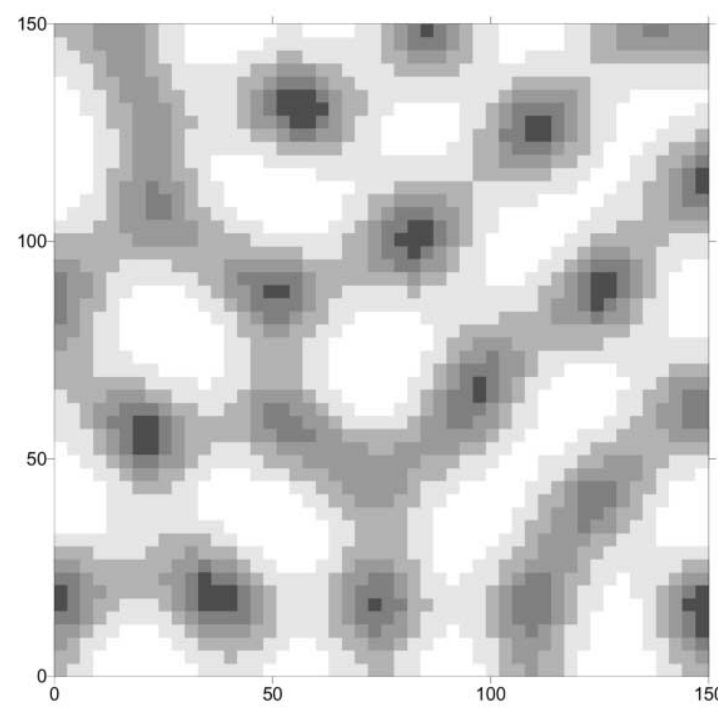

$\mathbf{a}$

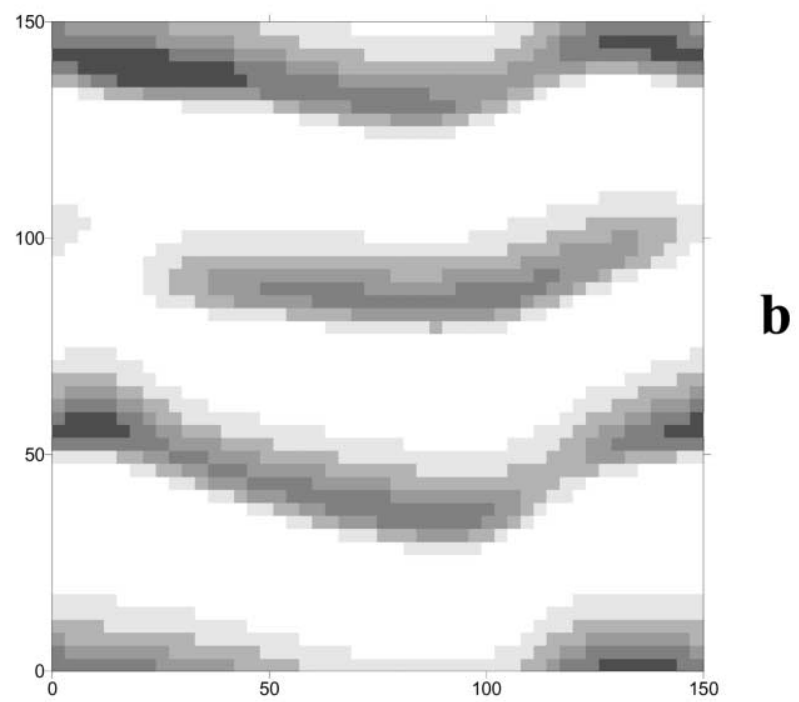

Figure 2: Spatial patterns of vascular plant biomass shown by gray colors; darker colors indicate a higher biomass. Values are given in six classes of equal intervals ranging from 179 to $1,171 \mathrm{~g} \mathrm{~m}^{-2}(a)$ and from 122 to $5,810 \mathrm{~g} \mathrm{~m}^{-2}(b)$. Scale is $150 \times 150 \mathrm{~m}$. $a$, Maze pattern on flat ground (after time $t=400$; nutrient input $N_{\text {in }}=1.4$, precipitation $p=0.5$, plant growth parameter $g=0.2$, rooting depth $h_{2}=-0.5$, other parameters set default; see table 1). $b$, String pattern on slope (after time $t=100$; nutrient input $N_{\text {in }}=1.5$, other parameters as in $a$ ).

realistic ranges for precipitation $p$ and atmospheric nutrient deposition $N_{\text {in }}$ for these latitudes were found in Semenova and Lapshina (2001) and UNEP/RIVM (1999), respectively (table 1 ). Other parameter values could not be checked against measured values in the Vasyugan bog complex in western Siberia. Therefore, the transpiration parameter $t_{\mathrm{v}}$ was checked by comparing simulated actual transpiration rates with measured growing season evapo- 


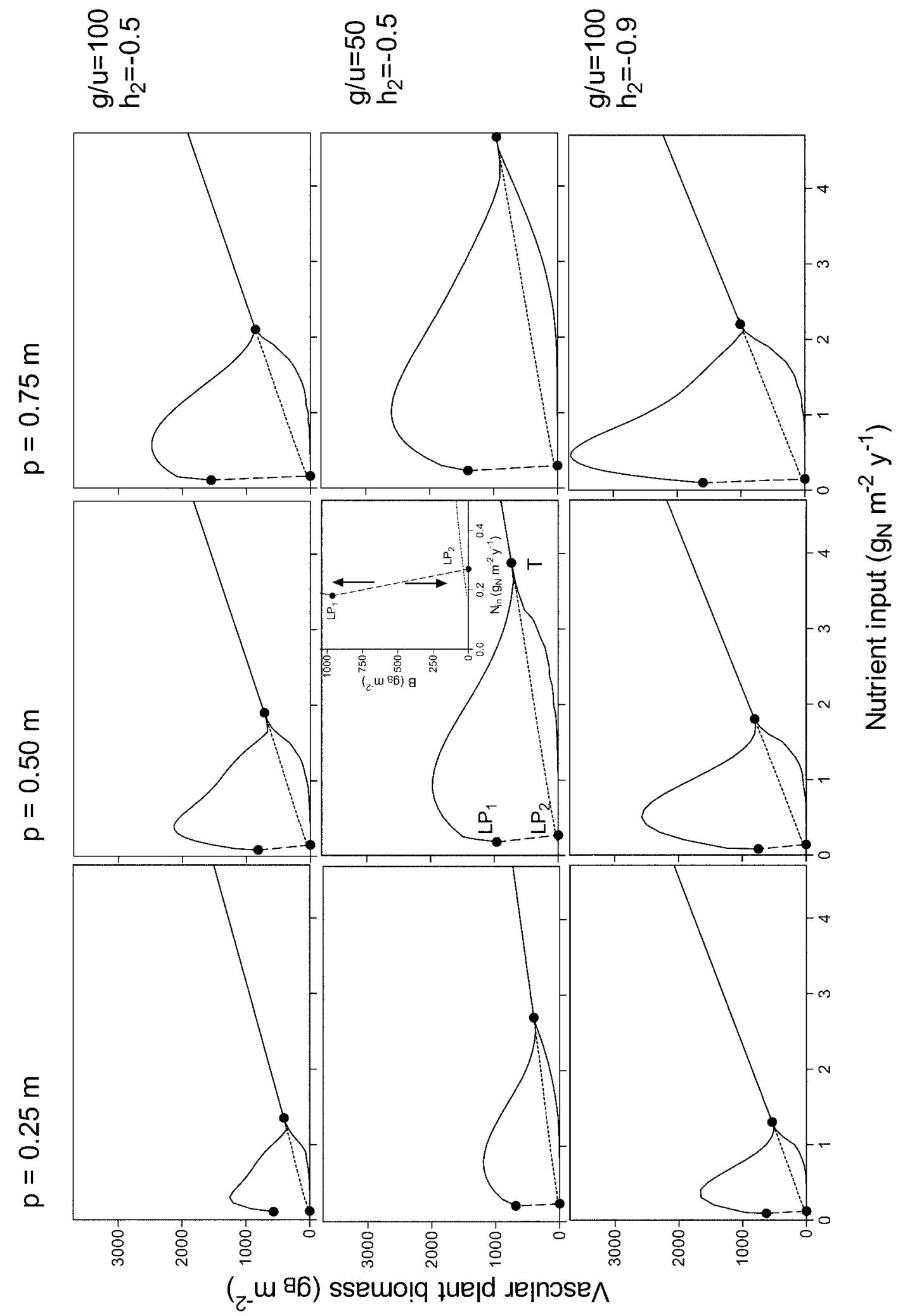


transpiration rates in the Bog Lake Peatland in northcentral Minnesota (Kim and Verma 1996), and the parameters $k$ and $\theta$ were derived from the study of Reeve et al. (2001) focusing on large peat basins as found in the Glacial Lake Agassiz region and the Hudson Bay Lowland, consistent with the saturated conditions in the Unsaturated Soil Hydraulic Database (UNSODA; Nemes et al. 2001). Other parameter values could not be checked against measured values in appropriate reference ecosystems. However, order-of-magnitude realistic estimates were assigned (table 1), and their values are not critical to the qualitative model results.

The equations were discretized, and simulations were run with forward Euler integrations. The spatial mesh consisted of a grid of $50 \times 50$ elements with reflecting boundary conditions. Grid size was $3 \times 3 \mathrm{~m}$, so the spatial mesh represents an area of $150 \times 150 \mathrm{~m}$. Simulations were started with random plant peaks $\left(200 \mathrm{~g}_{\mathrm{B}} \mathrm{m}^{-2}\right)$ in $10 \%$ of the grid elements, which were all set in the plantless homogeneous equilibrium of $H^{*}=p / e$ and $N^{*}=N_{\text {in }} / r$ (derived analytically assuming that $f(h(H))=H$; during the simulations $f(h(H))$ was the dimensionless function between 0 and 1 as explained in "Hydraulic Head"). For simulations, the program Matlab (MathWorks) was used, and simulations were run until stability was reached. In case of a slope, water flow was set in one direction with periodic boundary conditions. Our model could not be solved analytically; therefore, we performed a numerical bifurcation analysis to explore under which conditions pattern formation occurs in the model and the possibility of alternative stable states. For this, the spatial mesh consisted of a rectangular grid of $15 \times 15$ elements with a grid size of $5 \times 5 \mathrm{~m}$ in order to reduce calculation time.

\section{Results}

The typical spatial patterns that are generated by our model are revealed in a two-dimensional domain. On flat ground, a maze pattern is formed (fig. 2a). On slopes, where water flow was set in one direction, the model generates a string pattern (fig. $2 b$ ). These model results closely resemble observed patterns in the field (fig. 1 for maze patterns; see, e.g., Swanson and Grigal 1988 for string patterns).
In a numerical bifurcation analysis we now demonstrate how the maze patterns originate from the spatially homogeneous equilibrium. Further, we will show how this is affected by changes in the following abiotic and plant properties: nutrient input, precipitation, carbon/nutrient ratio of the plant (reflecting grams plant biomass produced per gram nutrient uptake), and rooting depth.

The model predicts a homogeneous equilibrium of vascular plant biomass, hydraulic head, and nutrient availability at relatively high nutrient input rates. With decreasing nutrient input, the homogeneous plant equilibrium decreases linearly, until it becomes unstable against small spatial perturbations at point $T$ (fig. 3 ). This is indicative of the principle of pattern formation as first outlined by Turing (1952). Therefore, we refer to this point as the "Turing instability point" (cf. HilleRisLambers et al. 2001; Rietkerk et al. 2002). From point $T$, as nutrient input decreases further, the homogeneous equilibrium does not exist, and stable nonhomogeneous equilibria occur that are illustrated by maximum and minimum local plant biomass (fig. 3). Mean vascular plant biomass for the whole two-dimensional domain is depicted by the dotted line. With further decreasing nutrient input, mean plant biomass and minimum local plant biomass decrease, while maximum local plant biomass first increases and then decreases until limit point $\mathrm{LP}_{1}$ is reached, beyond which all vascular plants go extinct. Once extinct, nutrient input has to be increased above limit point $\mathrm{LP}_{2}$ for vascular plants to recover. At nutrient input rates between $\mathrm{LP}_{1}$ and $\mathrm{LP}_{2}$, vascular plant biomass will recover only if their initial values are carried over the breakpoint values indicated by the dotted line connecting these two points (fig. 3, inset middle window). This indicates the coexistence of a homogeneous stable state with no vascular plants and a nonhomogeneous stable state where vascular plants can persist. Note that these alternative stable states exist only for a narrow but realistic parameter range.

An increase in precipitation leads to higher vascular plant biomass values as water stress is reduced (fig. 3, from left to right). At the same time, the range of nutrient input values for which spatial patterns are predicted (between $T$ and $\left.\mathrm{LP}_{1}\right)$ increases. This is because an increase in precipitation leads to an increase in hydraulic head, having a dilution effect on nutrient concentrations in the ground-

Figure 3: Bifurcation diagrams with nutrient input $N_{\text {in }}$ as bifurcation parameter for changing precipitation $p$, carbon/nutrient ratio of vascular plants $g / u$, and rooting depth $h_{2}$. Other parameters were set to the default values (see table 1 ). $B=$ vascular plant biomass, $T=$ Turing instability point, and $\mathrm{LP}_{1}$ and $\mathrm{LP}_{2}=$ limit points. At the right-hand side of $T$, the solid line represents stable homogeneous plant equilibria. At the left-hand side of $T$, the solid lines represent local minimum and maximum vascular plant biomass of the stable nonhomogeneous equilibria. The dotted line between these lines represents mean vascular plant biomass for the whole spatial domain. Inset middle window, dotted line between limit points $\mathrm{LP}_{1}$ and $\mathrm{LP}_{2}$ represents breakpoint values indicating alternative stable equilibria (homogeneous stable equilibrium with no vascular plants and nonhomogeneous stable equilibrium where vascular plants can persist); arrows indicate direction of change. 
water. Consequently, a homogeneous cover of vascular plants already breaks up, forming spatial patterns for higher values of nutrient input. A similar effect is predicted when decreasing the amount of plant biomass produced per gram nutrient uptake (fig. 3, upper two rows). In that case, vascular plants need to take up more nutrients for producing the same amount of biomass and therefore experience the same nutrient concentrations in the groundwater as being "diluted." At the same time, for relatively large ranges of nutrient input values, maximum local plant biomass is increased while mean plant biomass for the whole two-dimensional domain is decreased. This means that vascular plant cover is reduced and plants obtain nutrients from larger areas. In other words, decreasing the amount of plant biomass produced per gram nutrient uptake leads to a larger "resource area" of the plants.

An increase in rooting depth leads to higher biomass values as water stress is reduced, but this hardly affects the range of nutrient input values for which patterning is predicted (fig. 3, upper and lower rows). This is because vascular plants acquire additional nutrients from greater depth for equal nutrient concentrations and amounts of biomass produced per gram nutrient uptake. Because this leads to both higher local maximum biomass and higher mean biomass for the whole spatial domain, "resource area" of the plants is not affected.

\section{Discussion}

Our analysis shows that nutrient mass flow toward areas with vascular plants driven by transpiration (Fitter and Hay 1983; Marschner 1995) cannot be ruled out as a plausible mechanism for vegetation patterning in bog ecosystems. Although spatial differences in hydraulic head and nutrient availability may be small, this may lead to large differences in vegetation biomass. Our model differs from that of Swanson and Grigal (1988) in primarily two ways: it is fully mechanistic, and plants influence groundwater table height through transpiration instead of surface water table height through water ponding. Furthermore, our model provides a likely explanation for observed regular vegetation patterning on both slopes and flat ground.

Unlike the earlier models of Hilbert et al. (2000) and Pastor et al. (2002), our model is spatially explicit and therefore predicts spatial bifurcations from one stable state to another (homogeneous equilibrium without vascular plants, nonhomogeneous equilibrium with vascular plants, and homogeneous equilibrium with vascular plants), as both nutrient input and precipitation change (fig. 3). Our model results confirm those of Hilbert et al. (2000) and Pastor et al. (2002) in that they predict the possibility of multiple stable states. In Hilbert et al.'s (2000) model, an equilibrium of thin peat and high water table height co- exists with an equilibrium with thicker peat and lower water table height. In Pastor et al.'s (2002) model, communities of moss monoculture or communities where mosses coexist with vascular plants are alternative stable equilibria, the stability of either community depending on nutrient input-output budgets and life-history characteristics of the species. In our model, a homogeneous equilibrium without vascular plants coexists with a nonhomogeneous equilibrium with vascular plants. A coupling of these models will contribute to a more rigorous theory to account for how vascular plants and mosses influence, and are being influenced by, peat thickness, hydrology, and solute transport.

In order to reduce the complexity and increase the generality of our model, and to isolate the effect of the nutrient accumulation mechanism, we focused on vascular plants controlled by, and in turn controlling, both hydrology and solute transport. We did not include the peat layer, acrotelm thickness, and different functional plant groups (such as mosses, trees, grasses, etc.) as separate state variables. Nevertheless, our model could not be solved analytically, and we are currently exploring a different and more parsimonious route toward an analytically tractable model. Including the positive feedback mechanism between acrotelm thickness and increased production of vascular plants in case of flat ground, and the water ponding mechanism in case of a slope, would most likely reinforce the maze and string patterns produced by nutrient accumulation. At the same time, we do acknowledge that including the state variables mentioned above will expose additional complex dynamics (Pastor et al. 2002). However, because of our approach, we can now reveal an interesting common principle explaining vegetation patterning in different ecosystems, a subject to which we now turn.

Spatial self-organization may explain regular vegetation patterns observed in arid ecosystems, involving redistribution of water as a scarce resource (HilleRisLambers et al. 2001; Von Hardenberg et al. 2001; Rietkerk et al. 2002). As in water-limited ecosystems, we perceive spatial selforganization of vegetation in nutrient-limited systems as a reaction to resource scarcity, involving redistribution of nutrients. In the present model, vascular plants activate further growth by inducing nutrient mass flow toward the plants driven by transpiration, resulting in higher vascular plant biomass, feeding back to even higher transpiration and more nutrient accumulation. Therefore, vascular plants function as activators, facilitating plant growth nearby (1-m scale). At the same time, nutrient levels decrease farther away (10-m scale), inhibiting plant growth. This resembles the "activator-depleted substrate" system described by Meinhardt (1995). In order to allow stable pattern formation, sufficient substrate (nutrients) must be 
supplied to maintain a steady activator (plants) production, while lateral flow of the substrate must be higher than the diffusion of the activator. Our results confirm earlier model results, showing that redistribution of scarce resources may lead to fine-scale facilitative and coarsescale competitive plant interactions in different ecosystems (Lefever and Lejeune 1997; Couteron and Lejeune 2001; Lejeune et al. 2002; Rietkerk et al. 2002). Self-organization in ecosystems may be a more general phenomenon than previously thought (Rohani et al. 1997), which can be mechanistically linked to scale-dependent facilitation and competition.

\section{Acknowledgments}

We thank W. Bleuten, J. Couwenberg, P. de Ruiter, A. Grootjans, E. Lapshina, J. Pastor, I. Silva, J. van de Koppel, and one anonymous referee for their comments and useful discussions that significantly improved the manuscript. This study was supported by a grant from the Research Council Earth and Life Sciences of the Netherlands Organization of Scientific Research to M.R.

\section{Literature Cited}

Alexandrov, G. A. 1988. A spatially distributed model of raised bog relief. Pages 41-53 in W. J. Mitsch, M. Straskraba, and S. E. Jorgensen, eds. Wetland modelling. Elsevier, Amsterdam.

Belyea, L. R., and R. S. Clymo. 2001. Feedback control on the rate of peat formation. Proceedings of the Royal Society of London B 268:1315-1321.

Belyea, L. R., and J. Lancaster. 2002. Inferring landscape dynamics of bog pools from scaling relationships and spatial patterns. Journal of Ecology 90:223-234.

Couteron, P., and O. Lejeune. 2001. Periodic spotted patterns in semi-arid vegetation explained by a propagation-inhibition model. Journal of Ecology 89:616-628.

De Angelis, D. L. 1992. Dynamics of nutrient cycling and food webs. Population and Community Biology Series 9. Chapman \& Hall, London.

Feddes, R. A., P. J. Kowalik, and H. Zaradny. 1978. Simulation of field water use and crop yield. Simulation Monograph. Pudoc, Wageningen.

Fitter, A. H., and R. K. M. Hay. 1983. Environmental physiology of plants. Academic Press, London.

Foster, D. R., G. A. King, P. H. Glaser, and H. E. Wright, Jr. 1983. Origin of string patterns in boreal peatlands. Nature 306:256-258.

Hilbert, D. W., N. Roulet, and T. Moore. 2000. Modelling and analysis of peatlands as dynamical systems. Journal of Ecology 88:230-242.

HilleRisLambers, R., M. Rietkerk, F. van den Bosch, H. H. T. Prins, and H. de Kroon. 2001. Vegetation pattern formation in semi-arid grazing systems. Ecology 82:5061.

Kim, J., and S. B. Verma. 1996. Surface exchange of water vapour between an open sphagnum fen and the atmosphere. Boundary-Layer Meteorology 79:243-264.

Lapshina, E. D., N. N. Pologova, and E. Y. Mouldiyarov. 2001. Pattern of development and carbon accumulation in homogeneous Sphagnum fuscum-peat deposit on the south of West Siberia. Pages 101-104 in S. V. Vasiliev, A. A. Titlyanova, and A. A. Velichko, eds. West Siberian peatlands and carbon cycle: past and present. Proceedings of the International Field Symposium (Noyabrsk, August 18-22, 2001). Agenstvo Sibprint, Novosibirsk.

Lefever, R., and O. Lejeune. 1997. On the origin of tiger bush. Bulletin of Mathematical Biology 59:263-294.

Lejeune, O., M. Tlidi, and P. Couteron. 2002. Localized vegetation patches: a self-organized response to resource scarcity. Physical Review E 66:010901-1.

Lindsay, R. A., J. Rigall, and F. Burd. 1985. The use of small-scale surface patterns in the classification of British peatlands. Aquilo Ser Botanica 21:69-79.

Marschner, H. 1995. Mineral nutrition of higher plants. Academic Press, London.

Meinhardt, H. 1995. The algorithmic beauty of sea shells. Springer, Berlin.

Nemes, A., M. G. Schaap, F. J. Leij, and J. H. M. Wosten. 2001. Description of the unsaturated soil hydraulic database UNSODA version 2.0. Journal of Hydrology 251: $151-162$.

Okubo, A. 1989. Diffusion and ecological problems. Springer, New York.

Pastor, J., B. Peckham, S. Bridgham, J. Weltzin, and J. Chen. 2002. Plant community dynamics, nutrient cycling, and alternative stable equilibria in peatlands. American Naturalist 160:553-568.

Reeve, A. S., D. I. Siegel, and P. H. Glaser. 2001. Simulating dispersive mixing in large peatlands. Journal of $\mathrm{Hy}-$ drology 242:103-114.

Rietkerk, M., and J. van de Koppel. 1997. Alternate stable states and threshold effects in semi-arid grazing systems. Oikos 79:69-76.

Rietkerk, M., M. C. Boerlijst, F. van Langevelde, R. HilleRisLambers, J. van de Koppel, L. Kumar, H. H. T. Prins, and A. M. de Roos. 2002. Self-organization of vegetation in arid ecosystems. American Naturalist 160: 524-530.

Rohani, P., T. J. Lewis, D. Grunbaum, and G. D. Ruxton. 1997. Spatial self-organization in ecology: pretty patterns or robust reality? Trends in Ecology \& Evolution 12:70-74.

Sakaguchi, Y. 1980. On the genesis of banks and hollows in peat bogs: an explanation by a thatch line theory. 
Bulletin of the Department of Geography University of Tokyo 12:35-58.

Semenova, N. M., and E. D. Lapshina. 2001. Description of the West Siberian Plain. Pages 10-22 in W. Bleuten and E. D. Lapshina, eds. Carbon storage and atmospheric exchange by West Siberian Peatlands. FGUU Scientific Reports 2001-1. Physical Geography, Utrecht University.

Swanson, D. K., and D. F. Grigal. 1988. A simulation model of mire patterning. Oikos 53:309-314.

Turing, A. M. 1952. The chemical basis of morphogenesis. Philosophical Transactions of the Royal Society of London B 237:37-72.

UNEP/RIVM. 1999. A. F. Bouwman and D. P. van Vuuren. Global assessment of acidification and eutrophication of natural ecosystems. UNEP/DEIA\&EW/TR.99-6 and RIVM 402001012.
Von Hardenberg, J., E. Meron, M. Shachak, and Y. Zarmi. 2001. Diversity of vegetation patterns and desertification. Physical Review Letters 87:19.

Wassen, M. J., H. G. M. Olde Venterink, and E. O. A. M. de Swart. 1995. Nutrient concentrations in mire vegetation as a measure of nutrient limitation in mire ecosystems. Journal of Vegetation Science 6:5-16.

Yefremov, S. P., and T. T. Yefremova. 2001. Stocks and forms of deposited carbon and nitrogen in bog ecosystems of West Siberia. Pages 148-151 in S. V. Vasiliev, A. A. Titlyanova, and A. A. Velichko, eds. West Siberian peatlands and carbon cycle: past and present. Proceedings of the International Field Symposium (Noyabrsk, August 18-22, 2001). Agenstvo Sibprint, Novosibirsk.

Associate Editor: James P. Grover 